\title{
El sistema comercial internacional: Reflexiones a partir del Congreso de Viena ${ }^{1}$
}

\author{
The international trade system and the Congress of Vienna
}

JAIME TIJMES IHL ${ }^{2}$

Universidad de la Frontera, Chile

RECEPCIÓN: 3 I/O8/20I5 • ACEPTACIÓN: 04/03/20I6

\section{Introducción}

Este año se conmemora el bicentenario del Congreso de Viena. A nivel internacional, el tono general de estas conmemoraciones está marcado por distinguir y realzar las continuidades entre el Congreso de Viena y nuestros días ${ }^{3}$. En ese espíritu, esta breve reflexión pretende ofrecer un pequeño aporte a ese contraste entre dos épocas. En concreto, propondrá analizar ciertas facetas del Congreso que nos podrían permitir un diálogo provechoso con la situación actual del sistema comercial internacional, especialmente en lo que se refiere a los valores compartidos.

Lo anterior permitirá plantear la pregunta por el futuro del sustento con el que cuenta el sistema comercial internacional.

I. Esta publicación ha sido posible gracias al financiamiento del proyecto Fondecyt de Iniciación I I 145037.

2. Doctor en Derecho. Departamento de Ciencias Jurídicas, Centro de Investigación sobre Desafíos Internacionales, Núcleo de Ciencias Sociales, Universidad de La Frontera. Correo: jaime.tijmes@ufrontera.cl.

3. WERNER (2OI 5 ) pp. 3-8. 
TIJMES IHL

EL SISTEMA COMERCIAL INTERNACIONAL: REFLEXIONES A PARTIR DEL CONGRESO DE VIENA

\section{Valores compartidos}

En ocasiones puede ser enriquecedor establecer un diálogo entre fenómenos históricos disímiles: en este caso, entre el Congreso de Viena y la OMC. Por cierto, la elección puede resultar sorprendente. Sin embargo, el objetivo de este breve estudio no es insinuar un parentesco ideológico, histórico, ni de otro tipo entre ambos. El objetivo es mucho más modesto: simplemente indagar si a partir del Congreso de Viena podemos entender mejor algunos fenómenos de las relaciones comerciales internacionales actuales.

Es interesante destacar que, si bien el Congreso de Viena se dedicó primordialmente a lo que desde el siglo XX llamaríamos high politics, ya en el siglo XIX tuvo repercusiones para el comercio internacional. En efecto, uno de los resultados del Congreso fue una declaración contra el comercio de esclavos africanos ${ }^{4}$. Para evitar que continuase ese negocio, se encomendó a Inglaterra, que tenía los recursos navales necesarios, el rol de inspector de los puertos y de los barcos. Por cierto, Inglaterra no actuó solo por principios morales, sino también por consideraciones geopolíticas: ese nuevo rol le daba el prestigio de poder proclamarse como el adalid de la modernidad y le otorgaba una razón para controlar los mares. Es así como Inglaterra pudo asegurarse nuevas ventajas comerciales. Precisamente uno de sus intereses comerciales era hacer negocios en los mercados sudamericanos. A diferencia de su experiencia con sus ex colonias norteamericanas, con las cuales ya se habían normalizado las relaciones comerciales, Inglaterra no intentó colonizar ni conquistar $\mathrm{Su}$ damérica, sino que aplicó un instrumento que le resultaría mucho más barato: buscar instaurar un régimen de libre comercio con las repúblicas sudamericanas garantizado por la armada británica. Es así como una de las consecuencias mediatas del Congreso de Viena fue un impulso de liberalización comercial.

Pasando ahora al tema central de esta reflexión, uno de los muchos rasgos interesantes del Congreso de Viena se refiere a que los representantes diplomáticos (muchas veces aristócratas) compartían un cierto esprit de corps fundamentado en la pertenencia a una elite compuesta de personas que mantenían entre sí contactos personales y familiares fluidos ${ }^{5}$. El hecho de compartir ciertos rasgos culturales probablemente simplificó la comunicación entre los negociadores durante el Congreso y la solución de los conflictos que se

\footnotetext{
4. Véase Middel (2OI5) pp. I2-I4.

5. Véase Durchhardt (2015) p. 29.
} 
presentaron en las décadas posteriores. Algo análogo ocurría especialmente durante las primeras décadas de existencia del Acuerdo General sobre Aranceles Aduaneros y Comercio (GATT) (I947-I994), pues una de sus características más notorias era que estaba a cargo de representantes diplomáticos provenientes primordialmente de Estados del bando occidental de la Guerra Fría. Ellos compartían un ethos comunitario y autorreferente construido, entre otros, sobre la base de cordiales relaciones personalizadas y valores compartidos sobre el libre comercio, lo que, en definitiva, los encapsulaba del mundo exterior $^{6}$. Ahora bien, la OMC (desde 1995 hasta hoy), con su membrecía numerosa y heterogénea, ya no presenta esos rasgos, lo que ha provocado un cambio desde un paradigma diplomático hacia uno jurídico y, por tanto, con una tendencia más confrontacional. Lo anterior se puede observar en la solución de diferencias: al contrario del GATT, en la OMC la solución de diferencias no es voluntaria, los informes adoptados por el Órgano de Solución de Diferencias son vinculantes (art. 3, I 6 y I7.I 4 del Entendimiento Relativo a las Normas y Procedimientos por los que se Rige la Solución de diferencias de la OMC), existe el Órgano de Apelación, y se ha aceptado que las partes sean representadas por abogados externos ${ }^{7}$.

Lo anterior nos invita a reflexionar sobre las consecuencias posibles del cambio de ethos. El Congreso de Viena logró construir un concierto europeo estable que dio paz a Europa hasta la Guerra de Crimea. Si bien sería muy aventurado afirmar que esa guerra se haya debido a un debilitamiento del esprit de corps de los diplomáticos europeos, sí parece plausible que la existencia de un ethos común haya sido uno de los factores que permitió una paz duradera. Ahora bien, en los inicios del GATT las partes contratantes compartían una visión común respecto de la liberalización comercial, pero esa homogeneidad se fue diluyendo y en la década de 1980 el GATT se enfrentó a una crisis profunda ${ }^{8}$. Mas el hecho de que para las partes contratantes la solución a la parálisis haya sido una nueva ronda de negociaciones y que la Ronda Uruguay haya culminado en la creación de la OMC, es un indicio de que el ímpetu liberalizador seguía existiendo. En cambio, la Ronda de Doha comenzó en 200 I y, a estas alturas,

6. WEILER (200I) pp. I94-I95.

7. WeILER (200I) pp. I97-200. Respecto de los abogados externos, ver el Informe del Órgano de Apelación de la OMC, CE Banano III (WT/DS27/AB/R), párr. 5-I 2.

8. PAuwelyn (2005) pp. i 8-24. 
es improbable que alcance objetivos satisfactorios ${ }^{9}$. Al parecer, actualmente los miembros de la OMC carecen, por diversos motivos, de la determinación para lograr un acuerdo y concluir la Ronda. A un nivel más profundo, los órganos políticos de la OMC parecen estar paralizados. No parece descabellado preguntarse si una de las causas principales de la parálisis pudiese ser justamente la carencia de un ethos compartido entre los miembros de la OMC.

Sin embargo, el Congreso de Viena también enfrentó el desafío de la multiplicación de los actores internacionales. Para mejorar la gobernabilidad, Austria, Inglaterra, Rusia y Prusia acordaron tomar las riendas en la Alianza Cuádruple de Chaumont de I8I4, lo que, en definitiva, redujo la cantidad de actores ${ }^{10}$. Se pueden observar ciertas analogías con lo que ha ocurrido en el GATT y la OMC. Durante el GATT aumentó la cantidad de partes contratantes a raíz del proceso de descolonización durante las décadas posteriores a la Segunda Guerra Mundial, y más tarde continuaron las incorporaciones a la OMC y abarcaron por ejemplo a los Estados que habían formado parte del bloque soviético. Ahora bien, en el GATT y en la OMC ha habido mecanismos para reducir la cantidad de actores que negocian sin reducir la cantidad de partes contratantes del GATT ni de miembros de la OMC. Por ejemplo, en ocasiones un reducido grupo de Estados ha tomado la iniciativa para negociar en el llamado Cuarto Verde ${ }^{11}$. Tal vez en la época del Congreso de Viena la exclusión de ciertos actores se haya aceptado, pero en los tiempos actuales es difícil justificar la legitimidad de una decisión que no ha sido negociada por todos los involucrados ${ }^{12}$. Si a la exigencia de mayor inclusión en las negociaciones agregamos una membrecía con intereses diversos y a veces contradictorios, no resulta demasiado sorprendente que a los órganos políticos de la OMC actualmente les sea difícil adoptar decisiones.

Una de las enseñanzas del Congreso de Viena es que la capacidad de comunicación e interacción que sobrepase las barreras culturales y las fronteras nacionales es uno de los requisitos para construir un sistema internacional multipolar ${ }^{13}$. Tal como hacia I9I4 ya ni siquiera existía un consenso general

9. Sobre la Ronda de Doha, ver VanGrasstek (2013) pp. 4I3-46r; Bjornskov y LiND (2002) pp. 543-562.

iO. Middel (2015) p. IO.

i i. BLACKHURST (2000); JACKSON (200I) pp. 75-76.

I2. Pedersen (2006) pp. IO3-I3I.

i3. Marcowitz (2015) p. 25. 
respecto de la importancia de la idea rectora, fortalecida con el Congreso de Viena, de evitar una nueva gran guerra ${ }^{14}$, actualmente se parece estar desvaneciendo el consenso general sobre los beneficios del libre comercio. Esa falta de consenso podría ser una de las causas principales de los ya mencionados problemas de la Ronda de Doha de la OMC. También podría ser uno de los motivos de la aparición en los últimos años del fenómeno de los acuerdos mega-regionales, como el proyecto Transatlantic Trade and Investment Partnership (TTIP) entre la Unión Europea y los Estados Unidos, el proyecto Comprehensive Economic and Trade Agreement (CETA) entre la Unión Europea y Canadá y el proyecto Trans-Pacific Partnership (TPP) que está siendo negociado actualmente por Australia, Brunei, Canadá, Chile, Estados Unidos, Japón, Malasia, México, Nueva Zelanda, Perú, Singapur y Vietnam.

Queda abierta la pregunta si esa falta de consenso podría estarse extendiendo no solo a los representantes estatales, sino también a la población en general. Es así como, por ejemplo, en la Unión Europea los proyectos de una mayor liberalización comercial (tales como el proyecto de tratado TTIP con los Estados Unidos y el proyecto CETA con Canadá) parecen concitar un nivel relativamente alto de rechazo público. Sin embargo, esa cuestión quedará pendiente para una reflexión futura.

\section{Conclusiones}

Esta breve reflexión ha pretendido, por una parte, destacar que las influencias históricas en la construcción del sistema comercial internacional se extienden incluso al Congreso de Viena. En efecto, el empuje liberalizador del comercio que se observó en el siglo XIX se nutrió en parte de las consecuencias del Congreso.

Por otra parte, el Congreso de Viena nos permite subrayar la influencia que pueden tener los valores comunes entre los representantes de los Estados. Esos valores comunes son valiosos para construir y mantener un entramado institucional capaz de lograr objetivos tan disímiles como asegurar la paz o profundizar el sistema de comercio internacional. Sin embargo, tal como el consenso sobre la importancia de mantener la paz empezó a desvanecerse, algo similar parece estar ocurriendo respecto del apoyo que concita el sistema de comercio internacional.

I4. Marcowitz (20I 5 ) p. 26. 
TIJMES IHL

EL SISTEMA COMERCIAL INTERNACIONAL: REFLEXIONES A PARTIR DEL CONGRESO DE VIENA

La pregunta abierta es si ese apoyo se debilitará y cuáles podrían ser las posibles consecuencias. El objetivo de esta reflexión ha sido plantear precisamente esa pregunta.

\section{Referencias}

Bjornskov, Christian y Lind, Kim (2002): Where Do Developing Countries Go After Doha? An Analysis of WTO Positions and Potential Alliances. En Journal of World Trade 36(3), pp. 543-562.

BlackHuRst, Richard (200I): Reforming WTO Decision Making: Lessons from Singapore and Seattle. En Deutsch, Klaus y Speyer, Bernhard: The World Trade Organization Millennium Round: Freer Trade in the TwentyFirst Century, (Londres: Routledge), pp. 295-3 Io.

Durchhardt, Heinz (2015): Der Wiener Kongress und seine 'diplomatische Revolution'. En Kulturgeschichtlicher Streifzug. ApuZ 22-24, pp. 27-32.

Jackson, John (200I) : The WTO 'Constitution' and Proposed Reforms: Seven 'Mantras' Revisited. En Journal of International Economic Law, 4(I), pp. 67-78.

Marcowitz, Reiner (2015): Wiener Kongress I 8 I4/I 5 und Pariser Friedenskonferenz I919/20 - Zwei Friedenskulturen im Vergleich. En ApuZ, 22-24, pp. 2 I-26.

Middel, Matthias (2015): Der Wiener Kongress aus globalhistorischer Perspektive. En ApuZ, 22-24, pp. 9-I4.

Pauwelyn, Joost (2005): The Transformation of World Trade. En Michigan Law Review, I04(I), pp. I-65.

Pedersen, Peter (2006): The WTO Decision-Making Process and Internal Transparency. En World Trade Review, 5(I), pp. Iо3-I3 I.

Tijmes, Jaime (2009): Consensus and Majority Voting in the WTO. En World Trade Review, 8(3), pp. 4I7-437

VAngrasstek, Craig (2013): The History and Future of the World Trade Organization, (Ginebra: World Trade Organization), 646 p.

WeILER, J. (200I): The Rule of Lawyers and the Ethos of Diplomats: Reflections on the Internal and External Legitimacy of WTO Dispute Settlement. En Journal of World Trade, 35(2), pp. I9I-207.

Werner, Eva (2015): Ein Mahnmahl des Friedens - Der Wiener Kongress in den europäischen Erinnerungskulturen. En ApuZ, 22-24, pp. 3-8. 